\title{
A simple biodiversity assessment scheme supporting nature-friendly farm management
}

\author{
Erich Tasser ${ }^{\mathrm{a}, 1, *}$, Johannes Rüdisser ${ }^{\mathrm{b}, 1}$, Michaela Plaikner ${ }^{\mathrm{a}}$, Alexander Wezel $^{\mathrm{c}}$, Sibylle Stöckli ${ }^{\mathrm{d}}$, \\ Audrey Vincent ${ }^{\mathrm{e}}$, Heike Nitsch ${ }^{\mathrm{f}}$, Monika Dubbert ${ }^{\mathrm{g}}$, Valerie Moos $^{\mathrm{a}}$, Janette Walde ${ }^{\mathrm{h}}$, Daniel Bogner ${ }^{\mathrm{i}}$ \\ ${ }^{a}$ Institute for Alpine Environment, Eurac research, Drususallee 1, 39100 Bozen/Bolzano, Italy \\ ${ }^{\mathrm{b}}$ Institute of Ecology, University of Innsbruck, Sternwartestr. 15, 6020 Innsbruck, Austria \\ ${ }^{\mathrm{c}}$ Department of Agroecology and Environment, ISARA Lyon, 23 rue Jean Baldassini, 69364 Lyon cedex 07, France \\ ${ }^{\mathrm{d}}$ Department of Crop Sciences, Research Institute of Organic Agriculture (FiBL), Ackerstrasse 113, 5070 Frick, Switzerland \\ ${ }^{\mathrm{e}}$ Department of Social Sciences, ISARA Lyon, 23 rue Jean Baldassini, 69364 Lyon cedex 07, France \\ ${ }^{\mathrm{f}}$ Institute for Rural Development Research, Kurfürstenstr. 49, 60486 Frankfurt a.M., Germany \\ ${ }^{\mathrm{g}}$ Naturraumplanung Egger e.U., Bahnhofstraße 39/1, 9020 Klagenfurt, Austria \\ ${ }^{\mathrm{h}}$ Department of Statistics, Faculty of Economics and Statistics, University of Innsbruck, Universitätsstraße 15, 6020 Innsbruck, Austria \\ ${ }^{\mathrm{i}}$ Büro Dipl. -Ing. Dr. nat. techn. Daniel Bogner, August Jaksch Straße 59, 9020 Klagenfurt am Wörthersee, Austria
}

\section{A R T I C L E I N F O}

\section{Keywords:}

Alpine grassland

Farm monitoring

Biodiversity index

Butterfly abundance

Flower colours

Result-oriented agri-environmental measures

Shannon diversity index

Structuring degree

\begin{abstract}
A B S T R A C T
Farmers are important actors for regional development and biodiversity protection. Agri-environment-climate measures (AECM) are therefore a central tool of the European Union to support its biodiversity conservation policy. AECM generally reward farmers for fulfilling predefined management actions or avoiding specific practices. In contrast, result oriented AECM are intended to reward farmers for the outcome of nature friendly management practices. This approach gives more flexibility in management and hence promotes farmers engagement and autonomy. Besides educational activities and agricultural advisory services farmers need user friendly tools to assess biodiversity in order to meet result oriented AECM. Thus, we present a biodiversity assessment scheme for farmland using a set of indicators, which covers different aspects of biodiversity (flower colour index, butterfly abundance, landscape structuring degree, patch diversity index, aggregated biodiversity index) and can be applied at different spatial scales. The assessment scheme is applied on 44 farms in five countries (France, Switzerland, Germany, Italy, and Austria). To evaluate its appropriateness the relationship between the indicators and land-use intensity and plant species richness is investigated. Grasslands with low land-use intensity are more colourful grasslands, have significantly more butterflies and a higher aggregated biodiversity index than moderately and intensively used grasslands. The influence of management intensity on the landscape structuring degree is not significant. All indicators correlate with plant species richness at all spatial scales. The proposed assessment scheme serves as a tool for the detection of differences in biodiversity resulting from land-use practices, and can assist the monitoring of ROMs.
\end{abstract}

\section{Introduction}

Maintaining or restoring high levels of biodiversity in agro-ecosystems increases their resilience to climate change, supports the balanced provision of ecosystem services and contributes to habitat connectivity (Kremen and Merenlender, 2018). Biodiversity management and conservation hence constitute important issues in the management of landscapes with strong agricultural use. All European Union (EU) countries and many others have provided incentives to farmers to protect biodiversity, for example agri-environment-climate measures (AECM). AECM support farmers financially if they fulfil predefined management actions (e.g. mowing after a specified date or reducing fertiliser use). In recent years, result oriented measures (ROM), which target the actual changes in biodiversity due to farmers' management decisions have been developed and implemented (Burton and Schwarz, 2013; Herzon et al., 2018; Nitsch, 2014). ROM are for example the occurrence of specific, rare or protected species or a certain number of different species, these measures are independent of the management

\footnotetext{
* Corresponding author.

E-mail address: erich.tasser@eurac.edu (E. Tasser).

${ }^{1}$ E. T. and J. R. contributed equally to the work.
} 


\begin{tabular}{|c|c|c|c|c|}
\hline $\begin{array}{l}\text { Biodiversity } \\
\text { levels }\end{array}$ & Composition & Structure & Function & $\begin{array}{l}\text { Corresponding farming } \\
\text { system levels }\end{array}$ \\
\hline Genetic & - & - & - & $\begin{array}{l}\text { Animal breeds, } \\
\text { crop varieties }\end{array}$ \\
\hline $\begin{array}{l}\text { Population/ } \\
\text { Species }\end{array}$ & $\begin{array}{l}\text { Flower colours } \\
\text { Butterfly abundance }\end{array}$ & $\begin{array}{l}1-----2 \\
1 \\
1\end{array}$ & 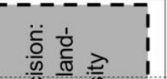 & Patch (field) \\
\hline $\begin{array}{l}\text { Community/ } \\
\text { Ecosystem }\end{array}$ & $\begin{array}{l}1 \\
1 \\
1\end{array}$ & $\begin{array}{l}\text { Structural degree } \\
1\end{array}$ & 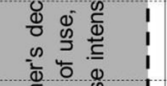 & Patch (field) \\
\hline $\begin{array}{l}\text { Regional } \\
\text { landscape }\end{array}$ & $\begin{array}{l}15-1-\cdots-1 \\
1=-1=-=-1\end{array}$ & $\begin{array}{l}\text { Patch diversity index } \\
\text { I }\end{array}$ & 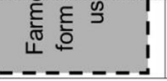 & $\begin{array}{l}\text { Farm, regional, } \\
\text { Inter-regional }\end{array}$ \\
\hline
\end{tabular}

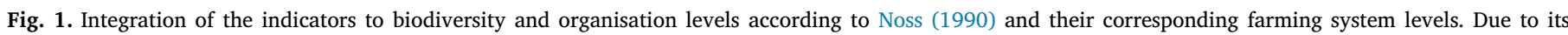
complexity, the genetic level is not covered by any indicator.

actions applied and offer farmers more flexibility, strengthen their responsibility and facilitate a critical and reflective analysis of farming practices and the implications for biodiversity conservation (Herzon et al., 2018). ROM have been applied exemplarily in Switzerland (as quality payments), France (the 'flowering meadows' measure), Germany (species-rich grasslands) and Austria (the results-based nature conservation plan, ÖPUL) (Nitsch, 2014).

To empower farmers to contribute to environmental and biodiversity protection, they need educational opportunities, farm-scale advisory service (Herzon et al., 2018) and user friendly tools for assessing easily biodiversity (Stoeckli et al., 2017). A suitable biodiversity assessment scheme provides farmers with reliable and cost-effective indicators to monitor and quantify different aspects of biodiversity on their farm. It should also deepen the farmers' understanding of the relationship between management practices and biodiversity. To facilitate farmer participation in such biodiversity assessment, the applied methods and indicators should cover as many aspects of biodiversity as possible, should be easy to understand and must find a balance between feasibility, informative value and sensitivity (Kuhn et al., 2011; Matzdorf et al., 2008). However, many existing biodiversity assessment schemes do not sufficiently meet these requirements. Most biodiversity indicators are limited to certain taxa (e.g. plants, grasshoppers, butterflies or birds) or specific habitats or habitat qualities (Nitsch, 2014; Stolze et al., 2015) and often require expert knowledge for assessment and interpretation. Most commonly, the abundance of plants are applied as biodiversity indicators (Nitsch, 2014). Plant species occurrences signal surrounding abiotic conditions (e.g. soil, topography and climatic conditions) and respond to human influences such as land use (Kuhn et al., 2011; Matzdorf et al., 2008; Tasser et al., 2009). Furthermore, plant species richness correlates significantly with overall biological diversity (Duelli and Obrist, 1998, 2003; Tasser et al., 2007). However, surveys of plant species richness are either limited to regionally developed lists of relatively easy recognizable indicator species or require expert knowledge. For a comprehensive assessment of biodiversity, a combination of various indicators is required (Duelli and Obrist, 2003; Rüdisser et al., 2015). In addition, indicators should allow farmers, stakeholders and policy makers to assess biodiversity on different spatial scales, ranging from a single field to the whole farm or the entire region. Indicators should also allow comparisons across farms and regions in order to learn from each other's success or failure.

In the context of an international study, investigating the applicability of ROM in the European Alps (Stolze et al., 2015), we develop and evaluate a biodiversity assessment scheme to support naturefriendly farm management.

The aims of this study are:

1) To develop a set of indicators to assess biodiversity on farmland in a comprehensive and cost effective way through a participatory process with stakeholders.

2) To evaluate the assessment scheme regarding its ability to compare the state of biodiversity at different spatial scales, ranging from a single field to whole farms and even entire regions.

3) To describe the relation of this indicator set to land-use intensity and plant species richness, the most commonly used biodiversity indicators in grasslands.

\section{Biodiversity assessment scheme for farmland}

The biodiversity assessment scheme, more specifically the selected indicators, are the result of a participatory process involving biodiversity experts and stakeholders including farmers and representatives from nature conservation organisations and administration. Based on a literature review on biodiversity indicators and AECM, an indicator list was developed in eight workshops in Austria, France, Switzerland and Germany, together with a total of 114 experts or stakeholders. Selection criteria for the final indicator list were a) their feasibility, b) practicability for non-professionals, c) suitability in covering different aspects of diversity and d) applicability at different spatial scales.

This process led to the selection of the four indicators a) flower colour index (FCI), b) butterfly abundance, c) structuring degree of agricultural patches and d) patch diversity index (Shannon diversity index, SHDI), as well as an aggregated index based on the four indicators. The proposed indicators, which were applied and evaluated in the pilot study, are assessed at patch level.

To assess biodiversity in a comprehensive way, applied biodiversity indicators should cover different spatial levels (genetic, population/ species, community/ecosystem and landscape) as well as different levels of organisation (composition, structure, function) (Noss, 1990). The species/population composition of the farm patches is represented by vascular flower colours and diurnal butterfly abundance (Fig. 1). The community/ecosystem level is covered by the structuring degree of the agricultural patches and the regional landscape level by the patch diversity index. The aggregated biodiversity indicator integrates the individual indicators and hence integrates information across spatial levels and components. Due to complexity and high analysis costs, no indicators for the genetic level have been integrated.

\subsection{Study regions and farms}

The biodiversity assessment scheme supporting nature-friendly farm management presented here was developed and evaluated in the context of a transnational study investigating the applicability of ROM (Stolze et al., 2015). The study enclosed five regions of the European Alps: the Upper Allgäu region in Germany, the Canton Lucerne in Switzerland, the Vercors region in France, the federal state of Carinthia in Austria and the province of South Tyrol in Italy (Fig. 2). The regions cover a broad spectrum of typical Alpine characteristics (Table 1).

In all study regions, farms representing the whole range of management intensity within the region were selected (Table 1 and Table A1). Eligible farms were pre-selected by local agriculture experts. The 


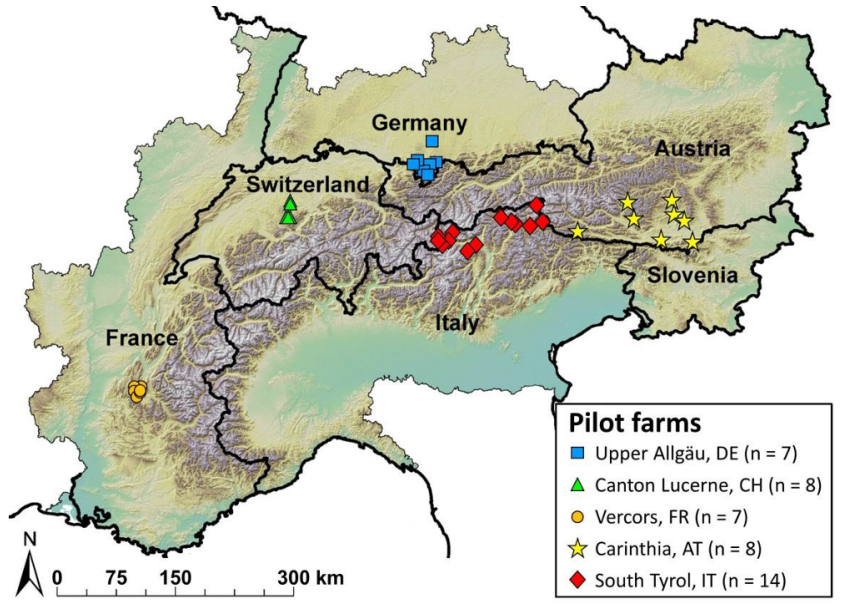

Fig. 2. Location of the 44 studied farms in the Alpine bow.

farmers were then asked to participate, and those who consented were included in the study. A total of 44 farms in the five study regions were investigated (Fig. 2, more details in Wezel et al., 2018). The average reduced Utilised Grassland Area (UGA) of the farms was 30 ha, but varied considerably among as well as within the study regions. In contrast to the UGA, the reduced UGA considers the yield potential of different sites and therewith enables a comparison between farms with different site conditions (e.g. mountain farms vs. lowland farms). Alpine pastures and mountain meadows produce only $12.5 \%$ of the yield of a meadow in the valley bottom (Hinojosa et al., 2019). Therefore, these areas are multiplied by 0.125 . The average reduced UGA in South Tyrol was 13 ha, whereas in Vercors, it was 80 ha (Table A1). However, in Vercors, individual farms varied between 32 ha and 110 ha in area. Of the 44 farms, 35 were specialised in dairying, cattle rearing or raising suckler cows. In Lucerne, half of the farms analysed raised pigs in addition to dairying. Most farms in Vercors raised sheep or goats. The average livestock density of the farms in the study varied between 0.6 livestock units (LU) per hectare reduced UGA in Vercors to $2.3 \mathrm{LU} \mathrm{ha}^{-1}$ in Switzerland.

\subsection{Indicator assessment}

\subsubsection{Identification of farm patches}

The assessment of the proposed indicators requires the identification of homogeneous farm patches. Using homogeneous farm patches instead of administrative field parcels allows to combine areas with the same plant composition to one patch. This can significantly reduce the workload in the field, especially in regions with many small parcels. In addition, a field parcel can consist of different patches due to topographical or land-use gradients. As we assessed plant species richness as a reference indicator for the evaluation of the indicator set, we conducted phytosociological surveys according to Braun-Blanquet (1964) and delineated patches based on homogeneous plant composition in the field. For this, a first farm patch was randomly selected, and a phytosociological survey was conducted on an area of $4 \times 4 \mathrm{~m}$, which corresponds to the minimum area in which $90 \%$ of all species of the most common hay meadows and fertilised pastures occur (Mueller-Dombois and Ellenberg, 1974). Starting from this first patch, all other areas of the farm were visited in succession. As soon as the species composition or phenology conspicuously changed, a new survey was carried out. The minimum area of the patches, which were mapped on a scale of 1:5000, was 0.25 ha. To corroborate the preliminary classification of the patches, the vegetation surveys were phytosociologically evaluated. The TURBOVEG programme (Hennekens and Schaminee, 2001) was used to digitise the vegetation records. For the phytosociological classification of the surveys, we used the JUICE programme (Tichy, 2002) in combination with a manual rearrangement (Braun-Blanquet, 1964).

The definition and delineation of homogeneous patches based on plant communities is a critical aspect of the proposed approach. In our study, this work was done by experts. In the case of future laypeople monitoring, also farmer or laypeople should be able to differentiate between patches based on visible differences in the vegetation. To facilitate this task, we developed a list of 20 characteristic plant species for the communities occurring in the study area (Lüth et al., 2011, Fig.

Table 1

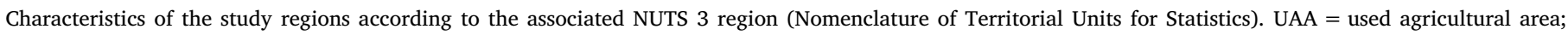
$\mathrm{TA}=$ total municipal area; $\mathrm{LD}=$ livestock density; $\mathrm{LU}=$ livestock units; GVA = gross value added of single sectors.

\begin{tabular}{|c|c|c|c|c|c|}
\hline & Upper Allgäu (DE) ${ }^{1)}$ & Lucerne $(\mathrm{CH})^{2)}$ & Vercors $(\mathrm{FR})^{3)}$ & Carinthia (AT) $)^{4)}$ & South Tyrol (IT) $)^{5}$ \\
\hline Population density $\left(\mathrm{n} \mathrm{km}^{-2}\right.$ ) & 89 & 256 & 49 & 58 & 7 \\
\hline Total area $\left(\mathrm{km}^{2}\right)$ & 1528 & 1493 & 1860 & 9546 & 74,010 \\
\hline Mean annual temperature (mean annual $\min / \max$ temperature) $\left({ }^{\circ} \mathrm{C}\right)^{7)}$ & $\begin{array}{l}6.4 \\
(1.7 / 11.1)\end{array}$ & $\begin{array}{l}6.8 \\
(3.3 / 10.7)\end{array}$ & $\begin{array}{l}7.6 \\
(2.8 / 12.5)\end{array}$ & $\begin{array}{l}6.3 \\
(1.4 / 11.2)\end{array}$ & $\begin{array}{l}4.3 \\
(-0.1 / 8.7)\end{array}$ \\
\hline Mean annual precipitation $(\mathrm{mm} \pm \text { s.d. })^{7)}$ & $1048 \pm 95$ & $1226 \pm 69$ & $1032 \pm 48$ & $1167 \pm 106$ & $827 \pm 79$ \\
\hline People employed in agriculture (\%) & 5.6 & 7.5 & 9.0 & 7.0 & 4.7 \\
\hline Number of farms (n) & 2206 & 4994 & 6310 & 16,715 & 20,247 \\
\hline Number of studied farms (n) & 7 & 8 & 7 & 8 & 14 \\
\hline UAA (ha) & 56,434 & 77,410 & 236,681 & 253,887 & 237,285 \\
\hline Share of UAA ( $\%$ of TA) & 34.5 & 54.2 & 37.4 & 26.6 & 32.0 \\
\hline Grassland (\% of UAA) & 99.7 & 81.6 & 37.6 & 74.7 & 88.1 \\
\hline Permanent crops ( $\%$ of UAA) & $<0.1$ & 0.6 & 4.3 & 0.1 & 10.2 \\
\hline Arable land (\% of UAA) & 0.2 & 16.9 & 58.1 & 25.1 & 1.6 \\
\hline $\mathrm{LD}\left(\mathrm{LU} \mathrm{ha}^{-1} \mathrm{UAA}, \text { mean } \pm \text { s.d. }\right)^{6)}$ & $1.0 \pm 0.4$ & $2.3 \pm 0.9$ & $0.6 \pm 0.2$ & $1.2 \pm 0.5$ & $1.6 \pm 0.4$ \\
\hline Change in farm numbers from 2000 to 2011 (\%) & -26 & -14 & -29 & -21 & -24 \\
\hline GVA agriculture (\%) & 2.1 & 1.6 & 0.9 & 2.0 & 4.8 \\
\hline GVA industry (\%) & 34.9 & 29.5 & 27.1 & 30.7 & 22.7 \\
\hline GVA services (\%) & 63.0 & 69.9 & 72.0 & 67.3 & 72.5 \\
\hline
\end{tabular}

Data:

1) Bayerisches Landesamt für Statistik-Jahresstatistik Allgäu 2014.

2) Bundesamt für Statistik (BFS)-STRU 2011, Landwirtschaftliche Betriebsstrukturerhebung 2011.

3) AGRESTE-recensement agricole 2013.

4) Statistik Austria-Agrarstrukturerhebung 2010, Überblick.

5) ISTAT-Censimento agricoltura 2010.

6) Calculated for the pilot farms-Data (Wezel et al., 2018).

7) Calculated for the pilot farms- Data from Worldclim (http://www.worldclim.org/). 
A2). We suggest using abundance classes such as 'single', 'several', 'common' and 'very common' instead of the more traditional BraunBlanquet (1964) method for assessing the frequency of these characteristic species. To test the list of character species, it was applied at all patches parallel to the phytosociological surveys. To obtain an automated classification of all relevés based on the character plant species, we used a discriminant analysis (DA, see Table A4) (Norušis, 1992).

\subsubsection{Biodiversity indicator}

2.2.2.1. Flower colour index (FCI). We propose to assess flower colour as a surrogate for plant species richness (see also Supplementary material). For a standardised survey of the indicator, however, some basic prerequisites must be taken into account: Primack (1985), Debieu et al. (2013) and Vidigal et al. (2016) indicated that natural variations in flowering times and flower longevity reveal strong latitudinal, altitudinal and temperature clines. The greatest variation in flowering colours cannot be found in spring (March, April), but rather later in the year, when the vegetation is more developed (Arnold et al., 2009). Therefore, we defined as the best time to survey the flower colours the vegetation peak, with shifts from May in lower altitude sites until August in higher altitude sites. Furthermore, to assess flower colour, a standardised colour key with the most common colours should be used to register flowers. The colours refer to the colours of the flower petals.

Flower colour was assessed in this study by counting the number of individual flowers per colour in a $16-\mathrm{m}^{2}$ survey plot, using three abundance classes (class 1: 1-5 individuals; class 2: 6-20 individuals; class 3: $>20$ individuals). To calculate the FCI, the three abundance classes were transformed into metric values by dividing the mean number of flowers per abundance class trough an assumed maximum of 50 individuals per colour. Hence, abundance class 1 (1-5 individuals, mean number of flours: 2.5 ) received the value of 0.06 , class 2 the value of 1.26 , and class 3 the value of 1.7. The FCI for a patch was then calculated by summing up the abundance values of all colours.

2.2.2.2. Butterfly abundance. Butterflies are excellent indicators for biodiversity assessments in the cultural landscape (Thomas, 2005, Hilpold et al., 2018) and serve as flagship species and help to communicate conservation goals to the general public (Feest et al., 2011). In order to survey the butterflies in this study, we applied a methodology for non-experts based on the work of Rüdisser et al. (2017). For surveys a predefined and visualised list of 13 characteristic butterfly species and 10 species groups was used. These species groups consist of taxa with similar appearance and habitat preference and cover most of the butterflies in Central Europe.

For those species and species groups the abundance was served in the field between $10: 00$ and $17: 00$ on warm $\left(>15^{\circ} \mathrm{C}\right)$, sunny to slightly cloudy days ( $<80 \%$ cloud cover). Wind speeds on the survey days did not exceed Level 3 on the Beaufort scale, which corresponds to a moderate breeze and a maximum wind speed of $19 \mathrm{~km} \mathrm{~h}^{-1}$.

2.2.2.3. Structuring degree. Heterogeneous landscapes provide more habitats for a variety of species and are therefore linked to higher biodiversity (Benton et al., 2003; Freemark and Kirk, 2001). Structuring elements can be individual, small and linear landscape features such as groves, hedges, single trees, banks or small habitats such as marshland, rocks and debris areas. In our case, the structuring degree in a landscape indicated the total number of structural elements per patch area and they were digitally assessed based on orthophotos on a scale of 1:5000 in ArcMap 10.2, but we tested in field also an assessment by counting single, non-contiguous structural elements within single patches.

2.2.2.4. Patch diversity index (SHDI). The Shannon diversity index of land-use patch types (SHDI) is used to evaluate patch diversity on farms. A higher SHDI corresponds to a greater number of patches (different grassland patches, different arable field patches) and a more uniform distribution of different patch types (Nagendra, 2002). Accordingly, the index can be calculated for the farm, regional and inter-regional levels.

2.2.2.5. Aggregated biodiversity index. The aggregated biodiversity index is used to summarise the total aspects of biodiversity and can be applied to the single patch, the farm (aggregated patch values per farm) or the regional or inter-regional level (aggregated farm values per region). To standardise the indicators (A), we propose the min-max scaling method with the highest and lowest regional or interregional value for each indicator:

$\mathrm{A}_{\mathrm{i}, \text { norm }}=\frac{A_{i}-A_{\min }}{A_{\max }-A_{\min }}$

Each indicator value is subsequently scaled between 0 and 1 . The regional maximum and minimum figures can be used to compare farms within a region, and the inter-regional maximum and minimum values can be used to compare farms in different regions. The min-max scaling method enables variables to have different means and standard deviations, but equal ranges, and provides a linear transformation of the original data.

\subsubsection{Fieldwork}

Fieldwork was conducted by project co-workers between May and August 2014, prior to the first cutting of the grasslands. During the fieldwork period, 235 phytosociological plant surveys, 201 flower colour surveys and 200 butterfly surveys were undertaken. For every single patch, all surveys were conducted at the same day and by the same person, using a visualised and standardised assessment form (Fig. 3). In a few cases, butterfly surveys or flower colour surveys could not be executed due to bad weather condition or a very early development stage of the vegetation, respectively, resulting in slightly reduced survey numbers as indicated. The development stage was assessed according to Nußbaum (1999), using the maturity stages of Taraxacum officinale and Dactylis glomerata, two of the most common grassland species. Plots with maturity stages higher then 3 (Taraxacum withered, Dactylis before flowering) were included. Usually, all surveys on a farm could be completed in 1 day. Due to logistical constraints, butterfly surveys were conduct only once per patch and not repeated during the season, as recommended by Rüdisser et al. (2017). Therefore, we did not analyse butterfly surveys at patch level, but pooled them by phytosociological patch type and region.

To evaluate the survey methods in the context of non-expert applicability, we asked farmers to join the experts executing the surveys, 13 out of 44 farmers ( 2 in AT, 8 in $\mathrm{CH}, 2$ in DE, 0 in FR, 1 in IT) accompanied the field work.

\subsection{Statistical analysis of the correlation between the suggested indicators and common biodiversity indicators}

Plant species richness is a meaningful and hence widely applied biodiversity indicator (Duelli and Obrist, 2003; Kuhn et al., 2011; Matzdorf et al., 2008; Tasser et al., 2009). We therefore compared plant species richness with the proposed indicator set at all spatial levels. Additionally, we evaluated the relations between land-use intensity and the suggested indicators. On the patch level, land-use intensity is derived from the classification of distinct phytosociological plant compositions. In accordance with the literature (Mucina et al., 1993) and expert opinion (see Table A3), we defined three land-use intensity classes: intensive, moderate and low input class. An intensively used grassland is mown and fertilised with slurry and/or manure twice or more times per year. A moderately used grassland is mown up to twice a year and fertilised once a year. Finally, a low input grassland is mown once a year or grazed, but not fertilised. On the farm level, livestock density (livestock unit per ha UAA) was used as an indicator for land- 


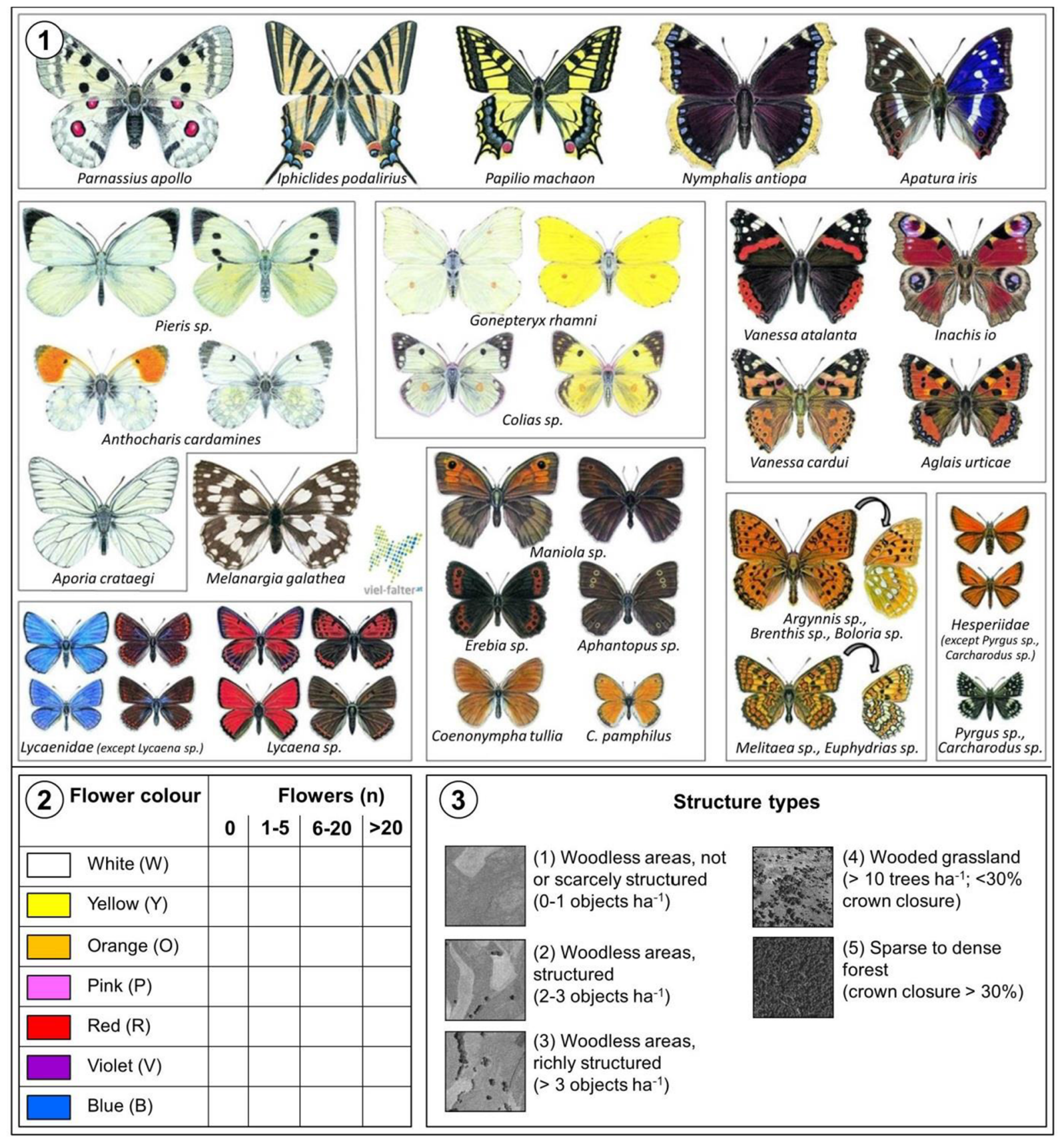

Fig. 3. Survey forms for fieldwork. (1) Diurnal butterflies (adapted from Rüdisser et al., 2017) with Melanargia galathea added, (2) flower colours: 0 to $>20$ represent the number of individuals counted within a survey plot $\left(16 \mathrm{~m}^{-2}\right)$ in which plant species have also been recorded; (3) structuring degree (modified from Tasser et al., 2009).

use intensity.

In order to assess whether the five individual biodiversity indicators provide similar information or whether they provide similar information as the common indicator plant richness, Pearsońs correlations were calculated between the single indicators. In a second step, statistical differences in biodiversity between land-use intensity classes on the patch level were tested with ANOVA and subsequent post-hoc tests. To investigate if and how the biodiversity indicators were influenced by land-use intensity and other site and land-use characteristics at the farm level, linear regression models (OLS) were used. Therefore, both site variables (mean altitude, mean annual temperature, mean annual precipitation) and land-use variables (LD, UAA, arable land in \% of UAA) were used as independent variables and each of the biodiversity indicators as dependent variables. Heteroscedastic robust standard errors were employed. Standardised regression coefficients (beta) as a measure to rank the variables according to their importance were used. All statistical tests were carried out at a significance level of $5 \%$ and if necessary a Bonferroni correction was employed. The statistical analyses were performed with the software package IBM SPSS statistics 24 .

\section{Results}

\subsection{Illustration of the application at different scales}

\subsubsection{Application on single patches}

The 235 phytosociological surveys were assigned to 24 plant community patches (Table A3). Different patches varied considerably in terms of biodiversity (see Table A3). The patches with the communities 

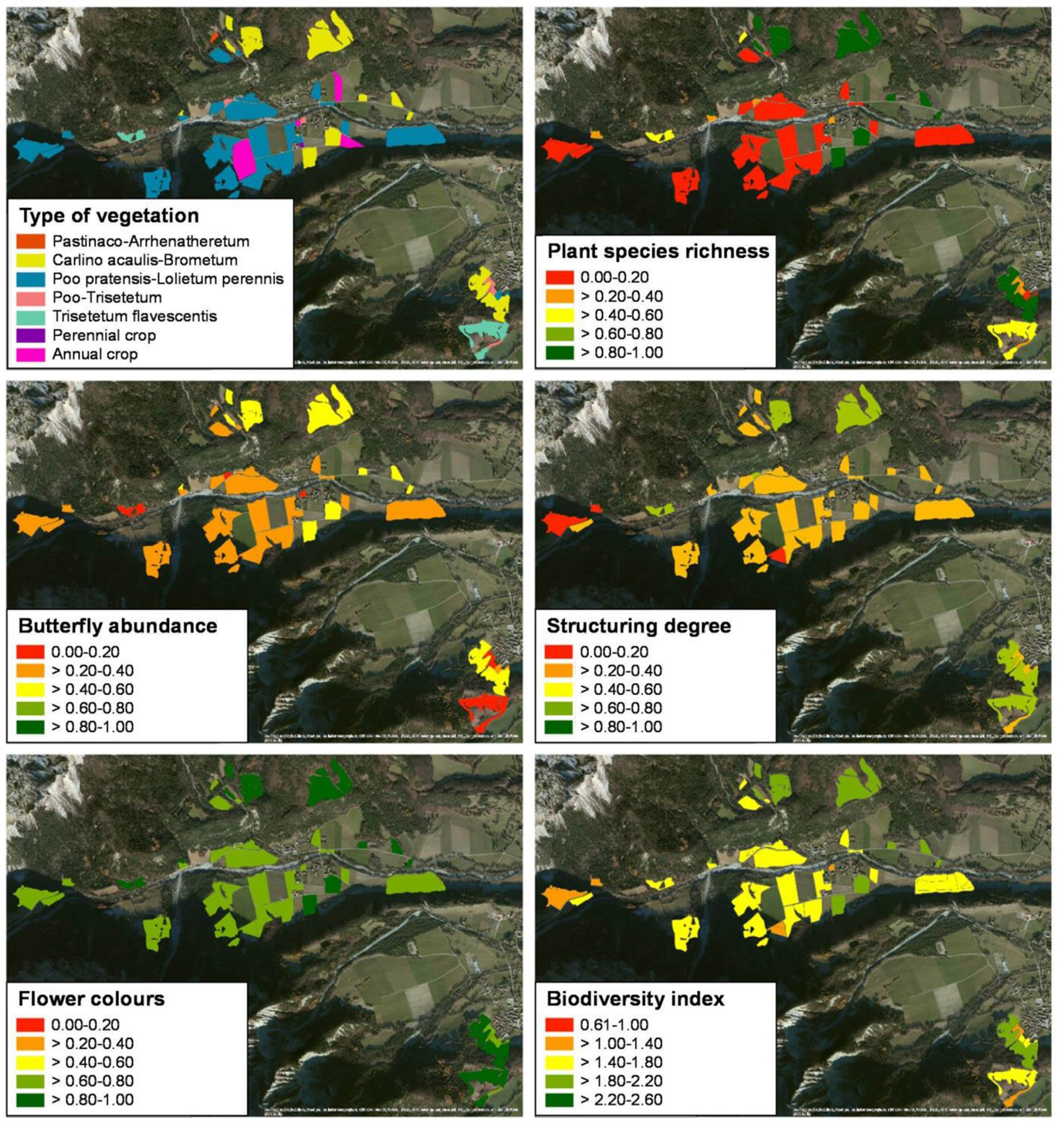

Fig. 4. Example of single-patch evaluation based on the four indicators on a single farm in France. All indicators were min-max standardised using regional benchmark values. The biodiversity index results from the sum of the indicators that were assessed at the single-patch level (aside from plant species richness).

Astrantio - Trisetetum, Festuco - Agrostietum and Onobrychido Brometum were particularly diverse, as portrayed by the indicators butterfly abundance and FCI. In contrast, Lolio perennis - Alopecuretum, Poo pratensis - Lolietum perennis and Arrhenatheretum montanum comprised communities that appeared to be particularly low in biodiversity in the respective patches. Patches classified as Arrhenatheretum montanum revealed a large farm-specific and regional variability regarding biodiversity. To illustrate the results at the patch level, standardised values for all indicators based on regional values were calculated and presented as maps. Fig. 4 illustrates the results for one farm in the French Vercors as an example.

We also tested the simplified approach of patch definition and delineation via characteristic plant species cover (Fig. A2). The results showed that a large range of grassland types could be distinguished by using these characteristic species (Table A4; 85\% correctly classified samples).

\subsubsection{Application at the farm level}

The state of biodiversity on farms can be illustrated by comparing all single patch indicators and the aggregated biodiversity index with the regional and interregional means of the studied farms via a graphical approach (Fig. 5). For this, we calculated the area-weighted mean values from all patches of the corresponding farm and then scored each farm indicator as a ratio of the regional (inter-regional) mean of this indicator. For example, the indicators of farm A in Vercors (Table A1: farm 17) scored in the middle range at the regional level and in the upper third at the interregional level for all single indicators. Farm B, a more intensively managed farm in Lucerne (Table A1: farm 9), was closer to the inter-regional minima across all indicators. The aggregated biodiversity index of all investigated farms ranged from a minimum of 


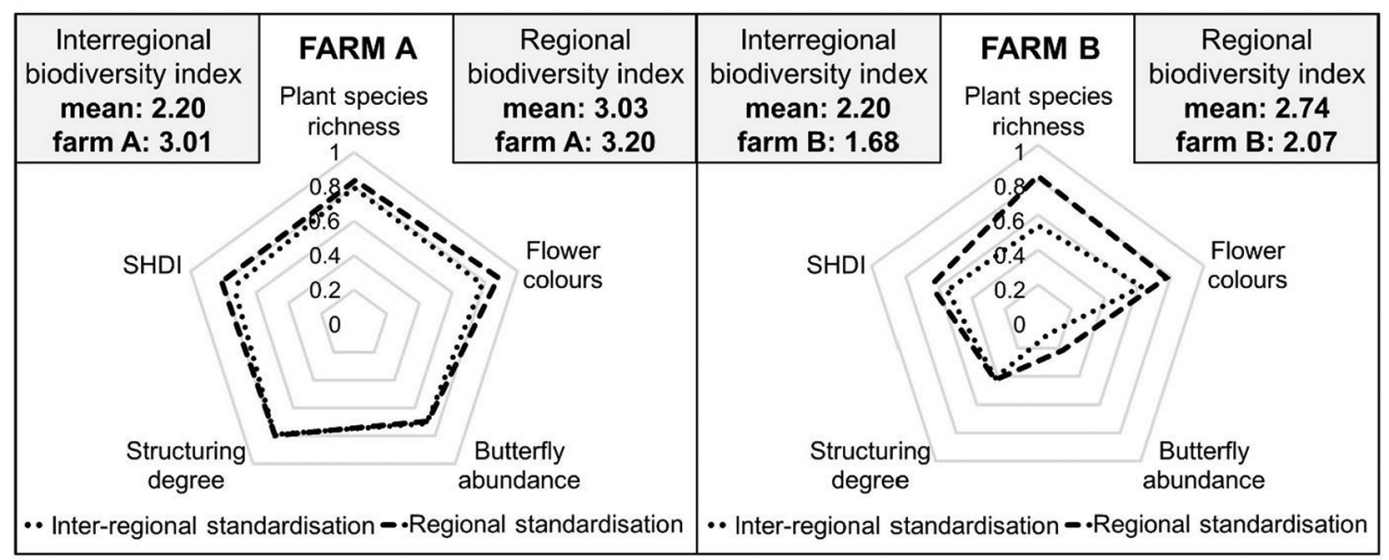

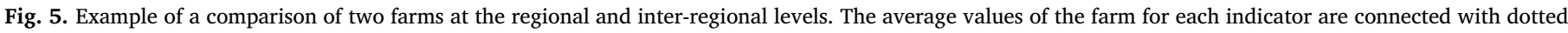

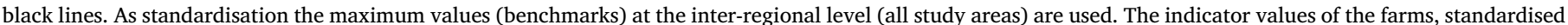

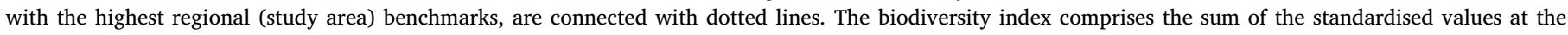
regional or inter-regional level.
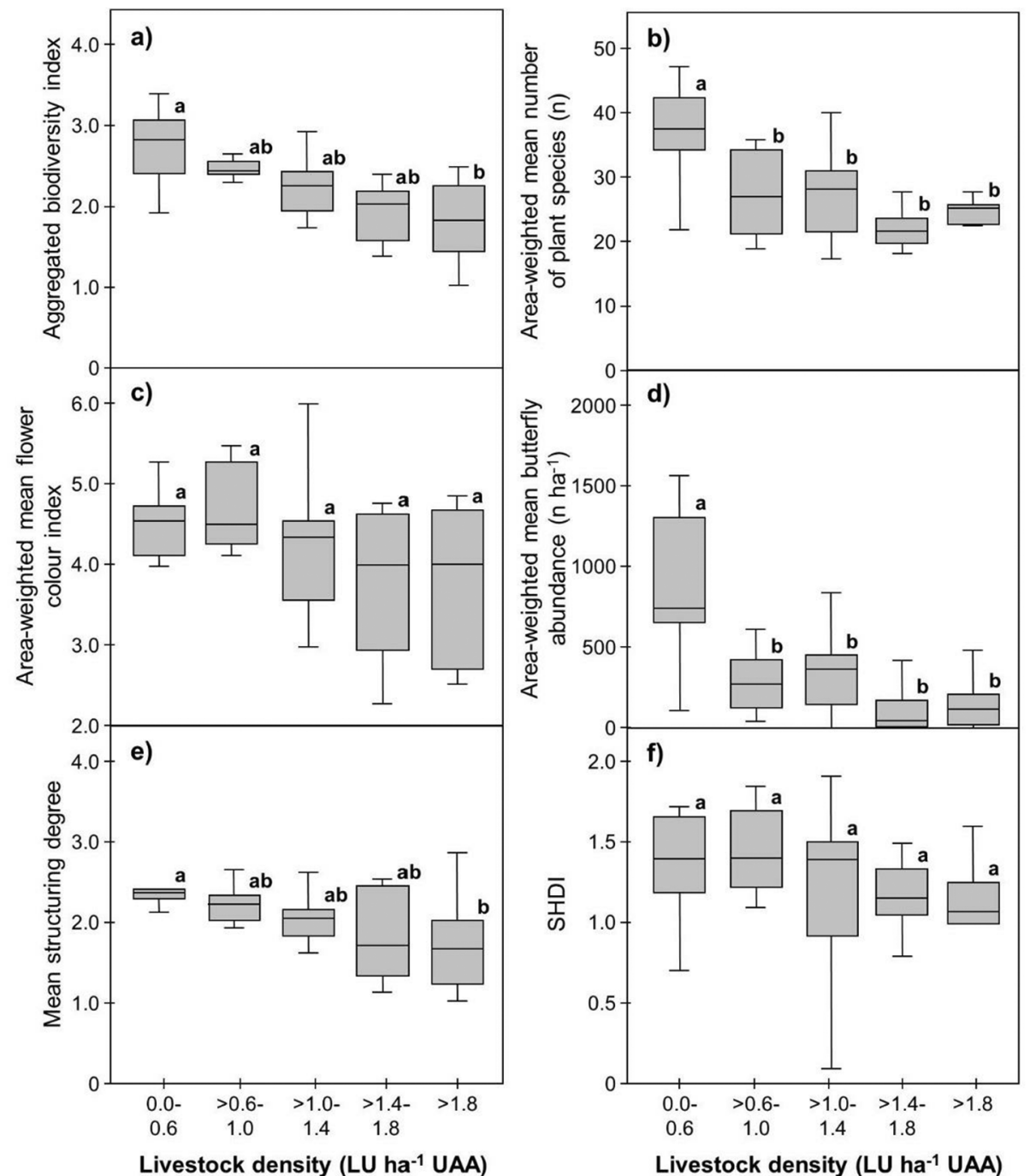

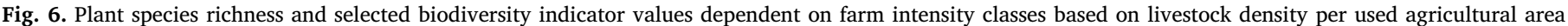
(UAA). Statistical differences between the groups were determined using post-hoc tests with Bonferroni corrected significance levels. 
1.02 to a maximum of 3.36 at the inter-regional level.

\subsubsection{Application at the inter-regional level}

The indicator set can also be used to compare different land-use intensity classes within or among regions (Fig. 6).

As a consequence of the predominant land-use intensity in the regions there are regional differences in biodiversity (Tables A6-7; Fig. A8). Regions with a high proportion of extensively used grasslands (e.g. farms in Vercors) scored highest in all indicators, whereas regions with highly intensive land use (e.g. Lucerne and South Tyrol) displayed lower values. Less intensively used farms have more colourful grasslands with greater plant species richness, higher rates of butterfly abundance and smaller structured and more diverse landscapes when compared with intensively used farms.

\subsection{Relation of the suggested indicators with common biodiversity indicators}

\subsubsection{Relation with plant species richness}

Plant species richness was significantly correlated with all indicators at the patch level (Table A5): FCI $=0.29$ (p < 0.01), butterfly abundance $=0.46(\mathrm{p}<0.01)$, structuring degree $=0.40(\mathrm{p}<0.01)$ and aggregated biodiversity index $=0.53(\mathrm{p}<0.01)$. The same was true at the farm level (Table A6), where plant species richness correlated with $\mathrm{FCI}=0.32 \quad(\mathrm{p}<0.05)$, butterfly abundance $=0.60$ $(\mathrm{p}<0.01)$, structuring degree $=0.33(\mathrm{p}<0.05)$ and the aggregated biodiversity index $=0.53(\mathrm{p}<0.01)$.

All significant correlations amongst the indicators were positive and all indicators were also positively correlated with plant species richness at all spatial levels, but the different, relatively low correlation coefficients (0.29-0.60) also indicated that the indicators in the set measured different aspects of biodiversity. The aggregated biodiversity index had on the contrary a high correlation with plant species richness.

\subsubsection{Relation with land-use intensity}

All indicators increased with decreasing land-use intensity (Table 2, Fig. 6). At the patch level, differences among the three intensity classes were significant for FCI $\chi^{2}(3)=9.924(p=0.019)$, butterfly abundance $\chi^{2}(3)=32.889(\mathrm{p}=0.000)$ and the aggregated biodiversity index $\chi^{2}(3)=25.697(\mathrm{p}=0.000)$ (Table 2). Differences of the structuring degree were not statistically significant $\left(\chi^{2}(3)=6.520\right.$; $\mathrm{p}=0.089$ ).

Plant species richness differed significantly among intensively used, moderately used $(\mathrm{p}<0.001)$ and low input grasslands $(\mathrm{p}<0.001)$. For the FCI, no significant differences were detected. Butterfly abundance was significantly higher in low input meadows in comparison with all other levels of intensity $(\mathrm{p}<0.001)$. The values of the aggregated biodiversity index differed among all intensity levels ( $\mathrm{p}<0.001)$.

At farm level, livestock density as a land-use intensity measure always had a negative impact on the biodiversity indicators (Table 3 ).
Furthermore, the altitude of the farms had a positive effect on the FCI and the aggregated biodiversity indicator, while mean annual temperature positively affected FCI and the structuring degree. Annual precipitation had a positive effect on FCI, butterfly abundance, structuring degree and the aggregated biodiversity indicator. The total UAA had a positive impact on butterfly abundance, SHDI and the aggregated biodiversity indicator.

\section{Discussion}

\subsection{Applicability of the indicator set}

To support biodiversity-friendly land-use and management practices, practitioners - in our case, farmers - need information and feedback about how their management practice influences biodiversity. The same is true in the context of ROM. We illustrated how the proposed assessment scheme enables comparison of field patches within a farm as well as the comparison of an entire farm with other farms on a regional or even inter-regional level. Consequently, this indicator set facilitates an integrated analysis and illustration of farmland quality in terms of biodiversity. The single indicators capture different facets of biodiversity, the aggregated index summarises these facets.

Although experts did all the assessment in the pilot study, we are convinced that the assessment for the indicator set could be executed by laypeople. This assumption is also supported by the farmers feedback. More than half of the farmers interviewed were certain that they were capable to conduct the proposed assessment on their farms if supported by regional advisory services (Wezel et al., 2018). This is furthermore reinforced by the outcomes of other monitoring and citizen science projects involving laypeople (Follett and Strezov, 2015; Kullenberg and Kasperowski, 2016; Rüdisser et al., 2017).

\subsection{Relation of the indicator with land-use intensity and plant species richness}

While traditional land use with low management intensity often generates habitat and hence species diversity, an increasing land-use and management pressure generally comes along with decreasing biodiversity (Newbold et al., 2015; Rüdisser et al., 2012). This concerns in particular anthropogenic grasslands, which are the predominant agricultural land-use types in the European Alps (Tasser et al., 2009). These grasslands, which are among the most diverse socio-ecological systems in the world, react extremely sensitively to altered land-use and management practices (Marini et al., 2009; Mucina et al., 1993; Niedertscheider et al., 2017, Niedrist et al., 2009, Tasser et al., 2009).

Although some grasslands in the European Alps are hot spots of biodiversity and therefore protected by the EU Habitats Directive (Council Directive 92/43/EEC), no standardised survey methods to assess and monitor biodiversity in anthropogenic grasslands at various levels and scales have yet been established. The most commonly applied indicator for assessing biodiversity has been plant species richness

\section{Table 2}

Biodiversity indicator values for different land-use intensities of meadows at patch level. Significant differences $(\mathrm{p}<0.05)$ in means of the biodiversity indicators between the land-use intensity classes were determined by Bonferroni corrected post-hoc tests. Statistically significant differences are indicated using different superscript letters $(\mathrm{a}, \mathrm{b}, \mathrm{c}, \ldots)$. All indicator data were collected at the same time and for the same patches. Due to unfavourable weather conditions (butterfly abundance) and different mature stage phases of the vegetation (flower colour), the absolute sample numbers (n) differ among the indicators.

\begin{tabular}{|c|c|c|c|c|c|c|c|c|c|c|}
\hline \multirow[t]{2}{*}{ Land-use intensity } & \multicolumn{2}{|c|}{ Plant species richness } & \multicolumn{2}{|c|}{ Flower colour index } & \multicolumn{2}{|c|}{ Butterfly abundance } & \multicolumn{2}{|c|}{ Structuring degree } & \multicolumn{2}{|c|}{ Biodiversity index } \\
\hline & $\mathrm{n}$ & $(\bar{x} \pm$ s.d. $)$ & $\mathrm{n}$ & $(\bar{x} \pm$ s.d. $)$ & $\mathrm{n}$ & $(\bar{x} \pm$ s.d. $)$ & $\mathrm{n}$ & $(\bar{x} \pm$ s.d. $)$ & $\mathrm{n}$ & $(\bar{x} \pm$ s.d. $)$ \\
\hline Intensively used grasslands & 72 & $19.5 \pm 5.6^{\mathrm{a}}$ & 72 & $4.13 \pm 1.20^{\mathrm{a}}$ & 60 & $118.8 \pm 279.2^{\mathrm{a}}$ & 72 & $1.98 \pm 1.2^{\mathrm{a}}$ & 60 & $0.75 \pm 0.28^{a}$ \\
\hline Moderately used grasslands & 126 & $27.6 \pm 8.6^{\mathrm{b}}$ & 92 & $4.31 \pm 1.38^{\mathrm{a}}$ & 110 & $313.7 \pm 479.7^{\mathrm{a}}$ & 126 & $1.98 \pm 0.74^{\mathrm{a}}$ & 110 & $0.88 \pm 0.28^{\mathrm{b}}$ \\
\hline Low input grasslands & 37 & $33.6 \pm 8.7^{c}$ & 37 & $4.60 \pm 0.64^{\mathrm{a}}$ & 30 & $899.8 \pm 860.9^{b}$ & 37 & $2.41 \pm 0.80^{\mathrm{a}}$ & 30 & $1.15 \pm 0.32^{\mathrm{c}}$ \\
\hline
\end{tabular}

Note: $\bar{x}$ denotes the mean, s.d. the standard deviation. 
Table 3

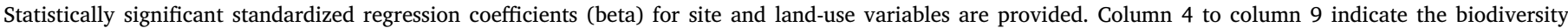

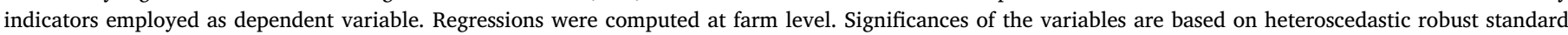

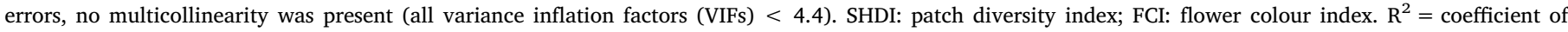
determination, Sig. = Significance of regression (ANOVA).

\begin{tabular}{|c|c|c|c|c|c|c|c|c|}
\hline \multirow[t]{2}{*}{ Dependent variables } & \multirow[t]{2}{*}{$\mathrm{R}^{2}$} & \multirow[t]{2}{*}{ Sig. } & \multicolumn{6}{|c|}{ beta of independent variables } \\
\hline & & & Altitude (m a.s.l.) & Temp. $\left({ }^{\circ} \mathrm{C}\right)$ & Precipit. (mm) & $\mathrm{LD}\left(\mathrm{LU} \mathrm{ha}^{-1} \mathrm{UAA}\right)$ & Arable land ( $\%$ of UAA) & UAA (ha) \\
\hline Plant species richness & 0.337 & 0.016 & & & $0.013^{*}$ & $-2.715^{+}$ & $0.178 *$ & \\
\hline FCI & 0.347 & 0.015 & $0.002 *$ & $0.327^{*}$ & $0.002^{*}$ & $-0.383^{* * *}$ & & \\
\hline Butterfly abundance & 0.690 & 0.000 & & & $0.668^{*}$ & $-81.113^{+}$ & $5.916^{*}$ & $7.722 * * *$ \\
\hline Structuring degree & 0.541 & 0.000 & & $0.101^{*}$ & $0.001^{* * * *}$ & $-0.335^{* * *}$ & & \\
\hline SHDI & 0.174 & 0.299 & & & & & & $0.006^{*}$ \\
\hline Aggregated biodiversity index & 0.599 & 0.000 & $0.001 *$ & & $0.001^{k * *}$ & $-0.179^{* *}$ & & $0.008^{* * * k}$ \\
\hline
\end{tabular}

$* * *=0.001$ significance level; $* *=0.01$ significance level; $*=0.05$ significance level; $+=0.1$ significance level.

(Nitsch, 2014) because of its ability to signal surrounding abiotic conditions (e.g. soil, topography and climatic conditions) and to respond to human influences (Kuhn et al., 2011; Matzdorf et al., 2008; Tasser et al., 2009). Plants also correlate with overall biological diversity (Duelli and Obrist, 1998, 2003; Tasser et al., 2007). However, the assessment of pant species richness demands expert knowledge and comprehensive training and can therefore not be executed by most farmers or other laypeople. We therefore did not include plant species richness in the indicator set, but rather used it as a reference variable in the pilot study. As we could show, the proposed indicator set correlates very well with species richness and covers even additional aspects of biodiversity (Table 2, Table A5, Supplementary material: Suitability of FCI for predicting plant species richness).

The entire indicator set reacted sensitively to land-use intensity at all spatial scales. In particular, the aggregated biodiversity index correlated consistently with land-use intensity. At the patch level, an intensification of grassland use (e.g. increased fertilisation and mowing frequencies) favours fast-growing nitrophilous grasses and herbs, causing slow-growing plants with lower nitrogen requirements to gradually disappear (Bakker and Berendse, 1999). Increased fertilisation also reduces butterfly abundance (Marini et al., 2009). The principal reasons for the positive correlation between low input grasslands and butterfly abundance have been attributed to the availability of forage plants in species-rich grasslands (Hawkins and Porter, 2003) and lower levels of disturbance (Hogsden and Hutchinson, 2004).

\subsection{Outlook and limitation of the proposed assessment scheme}

The operability of the proposed indicator set regarding administrative and logistical requirements was discussed thoroughly in stakeholder workshops (Stolze et al., 2015; Wezel et al., 2018). Farmers generally reacted very positively to the proposed methods for biodiversity assessment. Some farmers suggested that rewards based on ROM should include compensation for the additional effort related to the biodiversity assessments. To attain further knowledge regarding biodiversity and nature conservation and to identify the management practices that enhance biodiversity, adequate training and workshops should be offered (Wezel et al., 2018). To facilitate knowledge exchange amongst farmers, so-called 'expert farmers' could be designated and trained. Farmers with successful biodiversity measures could act as best-practice role models and share their management knowledge with interested colleagues. Furthermore, also competition actions between farmers about the biodiversity in meadows (e.g., "Flowering Meadows" in France) could contribute to change farmers' values and attitude towards biodiversity (Fleury et al., 2015). In this way, a network of farmers could be established, and over time, innovative forms of management could be designed, and successful but abandoned traditional land-use practices could be revitalised and promoted. The proposed biodiversity indicator set can help to improve farmers' knowledge about the influence of their management practices on biodiversity. This can foster awareness regarding their crucial role in biodiversity and ecosystem service protection. By enabling farmers to conduct more autonomous and informed management decisions, together with the effective monitoring of results, engagement and motivation for environmental protection activities in grasslands might be ameliorated (Lewandowski and Oberhauser, 2016).

The practical implementation of this biodiversity assessment in the context of AECM and ROMs will come with challenges and opportunities:

1) The involvement of farmers as lay experts has several advantages over other monitoring schemes. These benefits comprise: a) the selfinspection concept (i.e. having the farmer personally monitor the indicators) increases the farmerś responsibility for management decisions; b) by monitoring biodiversity on their own land, farmers learn about biodiversity; c) the frequency of official monitoring and inspection could be reduced, resulting in lower administrative costs; d) assessments by farmers provide valuable information to authorities, following the implementation of a particular measure regarding the status and changes in biodiversity on farms, without additional costs (i.e. for policy control and evaluation); e) the government's faith in farmers to effectively undertake monitoring can motivate the latter to engage further in biodiversity conservation.

2) ROMs could provide incentives for farmers in predominantly intensively used areas to shift to more extensive management forms. More intensively used grasslands with higher yields dominate agricultural land in the Alpine region and throughout the world, and therefore, the potential of these areas is high when adapted management practices such as postponed mowing are applied (Isselstein et al., 2005).

3) To improve biodiversity with ROM, time represents an important factor. The restoration of grasslands can take 10 to 100 years (Plantureux et al., 2005), depending on the intensification level and the time since intensification began. Recently intensified meadows restore more quickly than grasslands that have been intensified for a long period of time. It can take years or even decades for changes in biodiversity (and hence indicator values) to become effective. Therefore, the duration of the contract and the time considered for the evaluation of measures comprise important criteria that should be considered when designing ROMs. A long-term contract reduces the pressure on farmers regarding their common concern pertaining to risk exposure from potentially unpredictable, out-of-their-control factors, including prolonged droughts or other climatic variations (Wezel et al., 2018). Multi-year contract periods, combined with an annual indicator assessment, would provide a more realistic picture of biodiversity conditions and would minimise aberrations attributed to abnormal abiotic conditions in single years.

4) An option to encourage farmers to apply for ROM would be a 
graduate payment system that remunerates partially attained results (e.g. $50 \%$ of the required indicator species found) or predefined limits (e.g. biodiversity index of 1, 2 or 3) (Stolze et al., 2015). Furthermore, the achievement of predefined limits might not be proven each year, but rather in 3 out of 5 years or in 4 out of 7 years.

5) The indicators were assessed on patches with homogeneous vegetation composition. Hence, the delimitation of homogeneous patches provided the central basis for the field assessments. However, this step is not simple. A reproducible and verifiable delineation of these patches requires expert knowledge, or at the very least, substantial training of the farmers. We therefore propose that the initial survey is conducted by an expert, with the participation of the farmer. In the course of this joint survey, the farmer can be trained to recognise character species adapted to the local characteristics and homogeneous patches. Under the guidance of the expert, the farmer could already conduct all other indicator assessments. This would ensure adequate professional training and the supervision of the farmer.

6) For continuous monitoring and efficiency control, the farmer can count the flower colours and the butterflies as well as assess the structuring degree of the single patches every year. As the patch composition does not alter that quickly, changes should be documented only following significant changes. In this case, a re-mapping of patches by farmers under the control of an expert is recommended. The advantage of such combined monitoring would be that the farmer is directly integrated in the monitoring process and can immediately check measurements, while data quality can continue to be guaranteed through expert involvement.

\section{Conclusions}

We developed a set of indicators to assess biodiversity in a comprehensive and cost effective way on grassland farms and evaluated its applicability, with the aim to support biodiversity-friendly management practices. Our results indicate a high sensitivity of the indicator set to detect land use-related gradients on biodiversity. The indicator set could be used by authorities to control the implementation of measures (policy control) or by policymakers to evaluate the effectiveness of programmes (policy evaluation). The promotion of a straightforward biodiversity assessment scheme could broaden the target groups and allow larger numbers of farmers to participate in biodiversity observation on their farms. The indicator set proposed enables biodiversity analysis to be undertaken from different perspectives, addressing various components of biodiversity by combining compositional (faunal and floral) and structural aspects. In future, the indicator set is a feasible approach for biodiversity monitoring on grasslands, conducted by farmers.

\section{Acknowledgements}

First of all, we want to acknowledge the participation of the farmers in the five study regions and their sharing of ideas and knowledge. We are very grateful for the funding of the MERIT research project through the RURAGRI ERA-NET, supported by the European Commission under the 7th Framework Programme (FP 7, CA 235175). This work was also partly supported by the Federal Ministry of Science, Research and Economy (Top Citizen Science Initiative; TCS 12 Viel-Falter TCS). J.R. is part of the interdisciplinary research centre 'Ecology of the Alpine Region' within the major research focus 'Alpine Space' at the University of Innsbruck.

\section{Appendix A. Supplementary data}

Supplementary data to this article can be found online at https:// doi.org/10.1016/j.ecolind.2019.105649.

\section{References}

Arnold, S.E.J., Le Comber, S.C., Chittka, L., 2009. Flower color phenology in European grassland and woodland habitats, through the eyes of pollinators. Israel J. Plant Sci. 57 (3), 211-230.

Bakker, J.P., Berendse, F., 1999. Constraints in the restoration of ecological diversity in grassland and heathland communities. Trends Ecol. Evol. 14 (2), 63-68.

Benton, T.G., Vickery, J.A., Wilson, J.D., 2003. Farmland biodiversity: is habitat heterogeneity the key? Trends Ecol. Evol. 18 (4), 182-188. https://doi.org/10.1016/ S0169-5347(03)00011-9.

Braun-Blanquet, J., 1964. Pflanzensoziologie: Grundzüge der Vegetationskunde. Springer, Berlin.

Burton, R.J., Schwarz, G., 2013. Result-oriented agri-environmental schemes in Europe and their potential for promoting behavioural change. Land Use Policy 30 (1), 628-641.

Debieu, M., Tang, C., Stich, B., Sikosek, T., Effgen, S., Josephs, E., Schmitt, J., Nordborg, M., Koornneef, M., de Meaux, J., 2013. Co-variation between seed dormancy, growth rate and flowering time changes with latitude in Arabidopsis thaliana. PLoS One 8, e61075. https://doi.org/10.1371/journal.pone.0061075.

Duelli, P., Obrist, M.K., 1998. In search of the best correlates for local organismal biodiversity in cultivated areas. Biodivers. Conserv. 7 (3), 297-309.

Duelli, P., Obrist, M.K., 2003. Biodiversity indicators: the choice of values and measures. Agric. Ecosyst. Environ. 98 (1), 87-98.

Feest, A., van Swaay, C., Aldred, T.D., Jedamzik, K., 2011. The biodiversity quality of butterfly sites: a metadata assessment. Ecol. Ind. 11 (2), 669-675.

Fleury, P., Seres, C., Dobremez, L., Nettier, B., Pauthene, Y., 2015. "Flowering Meadows", a result-oriented agri-environmental measure: technical and value changes in favour of biodiversity. Land Use Policy 46, 103-114.

Follett, R., Strezov, V., 2015. An analysis of citizen science based research: usage and publication patterns. PLoS One 10 (11). https://doi.org/10.1371/journal.pone. 0143687. e0143687 EP.

Freemark, K.E., Kirk, D.A., 2001. Birds on organic and conventional farms in Ontario: partitioning effects of habitat and practices on species composition and abundance. Biol. Conserv. 101 (3), 337-350.

Hawkins, B.A., Porter, E.E., 2003. Does herbivore diversity depend on plant diversity? The case of California butterflies. Am. Nat. 161 (1), 40-49.

Hennekens, S.M., Schaminee, J.H.J., 2001. Turboveg, a comprehensive database management system for vegetation data. J. Veg. Sci. 12, 589-591.

Herzon, I., Birge, T., Allen, B., Povellato, A., Vanni, F., Hart, K., Radley, G., Tucker, G., Keenleyside, C., Oppermann, R., Underwood, E., Poux, X., Beaufoy, G., Pražan, J., 2018. Time to look for evidence: results-based approach to biodiversity conservation on farmland in Europe. Land Use Policy 71, 347-354.

Hilpold, A., Seeber, J., Fontana, V., Niedrist, G., Rief, A., Steinwandter, M., Tasser, E., Tappeiner, U., 2018. Decline of rare and specialist species acrossmultiple taxonomic groups after grassland intensification and abandonment. Biodivers. Conserv. 27, 3729-3744.

Hinojosa, L., Tasser, E., RÃ̃1/4disser, J., Leitinger, G., Schermer, M., Lambin, E.F., Tappeiner, U., 2019. Geographical heterogeneity in mountain grasslands dynamics in the Austrian-Italian Tyrol region. Appl. Geogr. 106, 50-59.

Hogsden, K.L., Hutchinson, T., 2004. Butterfly assemblages along a human disturbance gradient in Ontario, Canada. Can. J. Zool. 82 (5), 739-748.

Isselstein, J., Jeangros, B., Pavlu, V., 2005. Agronomic aspects of biodiversity targeted management of temperate grasslands in Europe-a review. Agronomy Res. 3 (2), 139-151.

Kremen, C., Merenlender, A.M., 2018. Landscapes that work for biodiversity and people. Science 362 (6412). https://doi.org/10.1126/science.aau6020.

Kuhn, G., Heinz, S., Mayer, F., 2011. Grünlandmonitoring Bayern: Ersterhebung der Vegetation 2002-2008. Bayerische Landesanstalt für Landwirtschaft, FreisingWeihenstephan.

Kullenberg, C., Kasperowski, D., 2016. What is citizen science? - A scientometric metaanalysis. PLoS One 11 (1). https://doi.org/10.1371/journal.pone.0147152. e0147152 EP.

Lewandowski, E.J., Oberhauser, K.S., 2016. Butterfly citizen science projects support conservation activities among their volunteers. Citizen Science: Theory and Practice 1 (1), 6 .

Lüth, C., Tasser, E., Niedrist, G., Dalla Via, J., Tappeiner, U., 2011. Plant communities of mountain grasslands in a broad cross-section of the Eastern Alps. Flora 206, 433-443.

Marini, L., Fontana, P., Battisti, A., Gaston, K.J., 2009. Agricultural management, vegetation traits and landscape drive orthopteran and butterfly diversity in a grassland-forest mosaic: a multi-scale approach. Insect Conserv. Divers. 2, 213-220. https://doi.org/10.1111/j.1752-4598.2009.00053.x.

Matzdorf, B., Kaiser, T., Rohner, M.-S., 2008. Developing biodiversity indicator to design efficient agri-environmental schemes for extensively used grassland. Ecol. Ind. 8 (3), 256-269.

Mucina, L., Grabherr, G., Ellmauer, T., 1993. Die Pflanzengesellschaften Österreichs-Teil 1: Anthropogene Vegetation, Teil 2: Natürliche waldfreie Vegetation, Teil 3: Wälder und Gebüsche. Fischer, Stuttgart.

Mueller-Dombois, D., Ellenberg, H., 1974. Aims and Methods of Vegetation Ecology. John Wiley and Sons, New York.

Nagendra, H., 2002. Opposite trends in response for the Shannon and Simpson indices of landscape diversity. Appl. Geogr. 22 (2), 175-186.

Newbold, T., Hudson, L.N., Hill, S.L.L., Contu, S., Lysenko, I., Senior, R.A., Börger, L., Bennett, D.J., Choimes, A., Collen, B., Day, J., De Palma, A., Díaz, S., EcheverriaLondoño, S., Edgar, M.J., Feldman, A., Garon, M., Harrison, M.L.K., Alhusseini, T., Ingram, D.J., Itescu, Y., Kattge, J., Kemp, V., Kirkpatrick, L., Kleyer, M., Laginha 
Pinto Correia, D., Martin, C.D., Meiri, S., Novosolov, M., Pan, Y., Phillips, H.R.P., Purves, D.W, Robinson, A., Simpson, J., Tuck, S.L., Weiher, E., White, H.J., Ewers, R.M., Mace, G.M., Scharlemann, J.P.W., Purvis, A., 2015. Global effects of land use on local terrestrial biodiversity. Nature 520, 45-50.

Niedertscheider, M., Tasser, E., Patek, M., Rüdisser, J., Tappeiner, U., Erb, K.-H., 2017. Influence of land-use intensification on vegetation C-stocks in an alpine valley from 1865 to 2003. Ecosystems 20 (8), 1391-1406.

Niedrist, G., Tasser, E., Lüth, C., Dalla Via, J., Tappeiner, U., 2009. Plant diversity declines with recent land use changes in European Alps. Plant Ecol. 202, 195-210. https:// doi.org/10.1007/s11258-008-9487-x.

Nitsch, H., 2014. Review on result-oriented measures for sustainable land management in alpine agriculture $\backslash \&$ comparison of case study areas. Report of Work Package, 1, 2013-2016. http://www.umweltbuero-klagenfurt.at/merit/.

Norušis, M.J., 1992. SPPS for Windows: Professional Statistics. SPSS, Chicago, pp. 348.

Noss, R.F., 1990. Indicators for monitoring biodiversity: a hierarchical approach. Conserv. Biol. 355-364.

Nußbaum, H., 1999. Grundfutterbewertung: DLG-Schlüssel zur Bewertung von Grünfutter, Silage und Heu mit Hilfe der Sinnenbewertung; eine Information des DLGAusschusses für Futterkonservierung und des DLG-Arbeitskreises Futter und Fütterung.

Plantureux, S., Peeters, A., McCracken, D., 2005. Biodiversity in intensive grasslands: effect of management, improvement and challenges. Agronomy Res. 3 (2), 153-164.

Primack, R., 1985. Longevity of individual flowers. Annu. Rev. Ecol. Syst. 16, 15-37.

Rüdisser, J., Tasser, E., Tappeiner, U., 2012. Distance to nature-a new biodiversity re levant environmental indicator set at the landscape level. Ecol. Ind. 15 (1), 208-216.

Rüdisser, J., Tasser, E., Walde, J., Huemer, P., Lechner, K., Ortner, A., Tappeiner, U., 2017. Assessing butterfly habitat quality in grasslands with data collected by pupils: simplified and still meaningful. J. Insect Conserv. 21 (4), 677-688. https://doi.org/ 10.1007/s10841-017-0010-3.

Rüdisser, J., Walde, J., Tasser, E., Frühauf, J., Teufelbauer, N., Tappeiner, U., 2015. Biodiversity in cultural landscapes: influence of land-use intensity on bird assemblages. Landscape Ecol. 30 (10), 1851-1863.

Stoeckli, S., Birrer, S., Zellweger-Fischer, J., Balmer, O., Jenny, M., Pfiffner, L., 2017. Quantifying the extent to which farmers can influence biodiversity on their farms. Agric. Ecosyst. Environ. 237, 224-233.

Stolze, M., Frick, R., Schmid, O., Stöckli, S., Bogner, D., Chevillat, V., Dubbert, M., Fleury, P., Neuner, S., Nitsch, H., Plaikner, M., Schramek, J., Tasser, E., Vincent, A., Wezel, A., 2015. Result-Oriented Measures for Biodiversity in Mountain Farming - A Policy Handbook. Research Institute of Organic Agriculture (FiBL), Frick.

Tasser, E., Sternbach, E., Tappeinera, U., 2007. Biodiversity indicators for sustainability monitoring at municipality level: an example of implementation in an alpine region. Ecol. Ind. 8, 204-223.

Tasser, E., Ruffini, F.V., Tappeiner, U., 2009. An integrative approach for analysing landscape dynamics in diverse cultivated and natural mountain areas. Landscape Ecol. 24 (5), 611-628.

Thomas, J.A., 2005. Monitoring change in the abundance and distribution of insects using butterflies and other indicator groups. Phil. Trans. R. Soc. B 360 (1454), 339-357.

Tichy, L., 2002. JUICE, software for vegetation classification. J. Veg. Sci. 13, 451-453.

Vidigal, D.S., Marques, A.C.S.S., Willems, L.A.J., Buijs, G., Méndez-Vigo, B., Hilhorst, H.W.M., Bentsink, L., Picó, F.X., Alonso-Blanco, C., 2016. Altitudinal and climatic associations of seed dormancy and flowering traits evidence adaptation of annual life cycle timing in Arabidopsis thaliana. Plant Cell Environ. 39, 1737-1748. https://doi. org/10.1111/pce.12734.

Wezel, A., Vincent, A., Nitsch, H., Schmid, O., Dubbert, M., Tasser, E., Fleury, F., Stöckli, S., Stolze, M., Bogner, D., 2018. Farmers' perceptions, preferences, and propositions for result-oriented measures in mountain farming. Land Use Policy 70, 117-127. 